\title{
Notas para uma Filosofia contra o Tempo ${ }^{\mathrm{i}}$
}

Ana Helena Amarante ${ }^{\mathrm{ii}}$

\section{Resumo}

Este trabalho, tangenciando principalmente uma atmosfera nietzscheana, como já sugere o título, quer deslocar a questão da utilidade da filosofia - o "para que serve?” - para uma questão que procura pela força da filosofia - “a quem aflige?”.

São inúmeras as respostas acerca da questão da utilidade da filosofia. A própria questão merece desprezo, pois já expressa uma necessidade de finalidade, à qual tudo se vê reduzido. Mas, muitas vezes, é interessante refazermos uma questão que há muito se julga inútil ou que já se tem argumentos de sobra para transpô-la. Então a questão aparece com alguma novidade, sem que as mesmas respostas que lhe deixavam morta, lhe satisfaçam.

Este trabalho, tangenciando principalmente uma atmosfera nietzscheana, como já sugere o título, quer deslocar a questão da utilidade da filosofia - o “para que serve?” - para uma questão que procura pela força da filosofia - “a quem aflige?”.

Partimos, portanto, da resposta que Nietzsche dá a pergunta sobre a utilidade da filosofia, e que segundo ele, está plena de ironia, merecendo uma resposta agressiva. A filosofia serve para afligir, denunciando toda a baixeza do pensamento. ${ }^{i i i}$ Mas é preciso dizer que a baixeza é sempre a do nosso tempo, é sempre "a nossa”, com a qual a filosofia se enfrenta.

E qual é, pois, a baixeza deste tempo? E que filosofia é capaz de enfrentá-la?

Antes de pensarmos um suposto conteúdo do nosso tempo que expressaria "nossa baixeza”, queremos pensar o próprio tempo, isto que chamamos “nosso tempo”.

Quando Nietzsche cria o conceito de intempestivo, ele o dirige a uma concepção tradicional do tempo, “imagem móvel da eternidade”, assim como a concebeu Platão, onde o tempo apenas revelaria um fundo pré-existente, uma totalidade primeira, um sentido original. Nietzsche retira o tempo da condição de prisioneiro da eternidade, para liberá-lo como força própria. Mas o intempestivo não se dirige somente à eternidade, o que parece mais fácil de conceber; mas ao "nosso tempo", ao tempo presente, mais precisamente, àquilo que "nosso tempo glorifica”.

Número 13: novembro/2009 - abril/2010 
Este parece ser o desafio desse conceito, pois colados ao tempo, em cada época, aderimos às suas exigências, comportando-nos conforme o tempo.

O intempestivo recusa tanto a eternidade como o tempo, isto é, ele inaugura um tempo que desfaz tanto uma concepção eterna, já dada; como uma concepção histórica do tempo, onde este seria distribuído entre os fatos que ocorrem à determinada vida. É possível aqui encontrar ressonâncias entre os dois modos bastante distintos de compreensão do tempo, na medida em que mantém o tempo inofensivo.

Já com a noção de intempestivo, o tempo recusa qualquer domesticação, saltando como que sobre o tempo cronológico, mesmo que a ele enlaçado: "agir de maneira intempestiva, quer dizer, contra o tempo, e assim sobre o tempo, em favor, eu espero, de um tempo que virá”. iv

É no tempo histórico, no desenrolar dos fatos que estamos irremediavelmente conectados, mas ao mesmo tempo, é também na recusa desse tempo histórico que algo de mais rico e abundante se insinua. Se a aderência ao tempo histórico faz perder de vista esta abundância, é justamente por se acreditar em sua primazia, em seu funcionamento ordenado e útil ao desenvolvimento de nossa civilização.

A aderência ao tempo histórico reúne o que o nosso tempo glorifica, faz-nos vigilantes, conscientes em demasia, o que Nietzsche compara com aquele que não consegue dormir. A insônia a favor de uma civilização que se enfraquece por não exercitar seu esquecimento, seu desapego à história. O esquecimento permite a novidade do tempo, a descontinuidade e a conseqüente leveza, já que a relação com o tempo histórico exige uma força específica para carregá-lo - nada mais distante do intempestivo.

Agir contra o tempo e sobre o tempo, talvez seja este nosso dilaceramento, uma nota grave que nos agarra ao tempo, com suas ordens corriqueiras, seus vícios mais cotidianos; e uma nota aguda que nos arranca do tempo ordinário, onde então, livres de sua gravidade experimentamos seu atordoante embaralhamento.

Como um monstro bizarro de patas distintas: uma, que pisa o passo do tempo atual, cotidiano, com todas as exigências da história; outra, que inventa permanentemente, passos de uma dança estranha que faz tropeçar a outra pata em sua costumeira marcha.

Antes que tentemos o equilíbrio dessa criatura de passo híbrido, antes que evoquemos nosso tentador procedimento de escolha entre uma pata e outra, ou que façamos esse passo ser 
convertido em plácida síntese; observemos esta composição com cada elemento que possui, considerando principalmente esta "rasteira” que não permite o encadeamento do passo.

É que o intempestivo não se encaixa no tempo, embora seja no tempo que ele age. Sua força reside no fato de que ele é extemporâneo, sem estar simultaneamente fora do tempo. É uma extemporaneidade no tempo, forçando o pensamento e a vida a sua mais íntima propriedade: a novidade, a pura variação.

Para tanto, a ação intempestiva volta-se contra o tempo, contra àquilo que é excessivamente contemporâneo, ou seja, aquilo que cabe no tempo, aquilo que nosso tempo permite, reifica e sustenta como sendo seu.

Agir contra o tempo é resistir a sua confortável contemporaneidade, e aqui encontramos nossa questão: discernir essa resistência de uma mera oposição ao tempo, com suas figuras fatigadas de crítica. Isto porque, ao pensarmos o trabalho filosófico, seja ele de ensino ou outro, deparamo-nos com uma necessidade constante de provocar um estranhamento com aquilo que nosso tempo glorifica.

Nessa tentativa de provocação, procurando como que um atrito que desaloje o pensamento de uma conformação ao tempo, muitas vezes parece impossível não partir de uma oposição. Nossa questão é de que a oposição ao tempo também é o que o nosso tempo glorifica. E talvez esta seja uma estupidez ou baixeza, própria deste tempo. Mecanismo que se apresenta como possibilidade de suportar o tempo, carregando simultaneamente uma impotência que acaba por encaixar-se, uma outra vez, em “nosso tempo”.

Toda a oposição respeita, de alguma maneira, o lugar de privilégio da posição primeira. Está referida a ela, e prisioneira do próprio mecanismo que condena. A oposição acredita em outra ordem possível que ela mesma representaria ou estaria apta a garantir, caso tomasse a "posição", mantendo assim, uma relação de identidade com a posição a qual se opõe.

Opor-se a determinada ordem é condenar-se a esta mesma ordem, é admiti-la como ordem - é obedecê-la. No entanto, a oposição, há muito, aparece como a forma de resistência por excelência, quando então reagimos ao que nos assola. ${ }^{\mathrm{v}}$

A oposição acabou assumindo o lugar legítimo da luta, onde luta e oposição são termos correspondentes, mas sempre remetidos a posição na qual se opõem.

Este modo de resistir surge já impotente, desnutrido de uma força própria; a força é sempre do outro. Este esvaziamento de força é próprio das mazelas do nosso tempo, onde se 
acredita na posse de uma força particular, sem de fato possuí-la. A reação como uma ação, a mais legítima, quando plenos dessa força opositora, nos sentimos participantes, atuantes, em luta, à espera de outra possibilidade.

Percebe-se que há um modo de resistir encarnado na reação, e também em um modo de subjetivação característico; isto é, um modo de experiência num mundo que já está dado, onde o pensamento é somente um conjunto de categorias para explicá-lo, e a vida, disposta em estereótipos bem fundados, apenas espera ser compreendida por essas categorias. Assim, a reação opositiva, espera o momento em que poderá finalmente exercer o poder, pois guarda uma possibilidade já feita, ela “já sabe” como agir, caso tome a posição. Ela já sabe o que é necessário, mas sem dar-se conta de que, isto que julga uma necessidade, está em conformidade com o mundo já posto.

Este “já saber” encerra a possibilidade em algo que pré-existe, faltando-lhe apenas, a realização. O que é possível, já mantém assim, uma estreita relação de identidade com o que deverá ser realizado, antes da realização e quando se realiza. A realização é correspondente ao possível que é, neste caso, conformado a um mero desdobramento de algo que já se encontrava em estado embrionário.

Encontramos esta crença nas entranhas do nosso pensamento. A distinção aristotélica entre ato e potência traz esta passagem do possível ao real. O que se realiza já estava contido na possibilidade. A mudança que ocorre é definida pela passagem da potência ao ato, quando há a concretização ou materialização daquilo que já existia em potencial. O que vemos aí é um mundo dado para um sujeito estruturado substancialmente, pois as mudanças que vão ocorrendo (no mundo e no sujeito) apenas referem-se à realização já pressuposta, ou seja, há um substrato imóvel que permanece o mesmo. Sujeito e mundo vão sendo formados a partir de um critério de identidade com esse pré-existente.

Se acreditar em outra possibilidade é já contê-la, é porque mantemos, no conceito de possível, esta estrutura. Dessa maneira, a resistência que se pretende crítica/ opositora, espera por outro mundo, guardando a realização dessa possibilidade.

Deleuze, na esteira de Bergson, anuncia que o possível não se tem previamente, mas tem de ser criado. Se ele é criado, não poderá mais obedecer a uma lógica anterior a esta criação, mas será necessariamente engendrado como novidade absoluta. ${ }^{\text {vi }}$ Se o possível é criado é porque não há nada fora das condições mesmas dessa criação definindo-o, ou seja, as próprias condições que se fazem na emergência deste “campo de possíveis”.

Número 13: novembro/2009 - abril/2010 
Portanto, possibilidade não é o que já existe como alternativa, nem a realização à imagem do que uma vez já se sonhou, já se desejou, mas é possibilidade criada e não mais realizada.

Por isso dois modos de resistência aqui se impõem: um modo fundado na reação, na crítica como oposição, que guarda e espera o momento de realizar um projeto previsto - o que não chamaremos mais de resistência; outro modo, onde resistir é necessariamente criar, “criar entre impossibilidades”, vii encontrar saídas que não existiam antes.

Resistir se distingue de reagir, ${ }^{\text {viii }}$ portanto a resistência que se ancora na reação, o que aqui chamamos de crítica opositora, não é resistência, mas uma reação cansada, prisioneira de uma relação transcendente.

Transcendente porque supõe a existência de algo fora das condições do "plano de imanência” que fornece o valor e o sentido. Ou seja, o que define a vida nesse caso é justamente a falta de realização de uma possibilidade sonhada, de outro mundo, de outro projeto político, de algo que já existe como possibilidade, mas que ainda não se realizou; o que se configura numa espécie de esperança que aguarda o momento em que finalmente poderemos viver conforme nosso projeto pré-concebido. Então a crítica em forma de oposição, aparece como falsa resistência, pois nada produz a não ser o mesmo mundo.

Uma filosofia que se ancora na reação produz o mesmo mundo, mesmo que com a máscara de uma “outra possibilidade”. É uma filosofia que “não aflige ninguém”, pois apenas lida com o maciço tempo atual, o tempo histórico, prestando-lhe contas eternamente. É uma filosofia que não se deixa assaltar pelo intempestivo, pois necessita partir de algum lugar, um ponto de apoio que a crítica, entendida aqui como oposição, lhe oferece.

A novidade do tempo não está, definitivamente, na oposição a ele, mas ao que dele escapa, ao mesmo tempo em que dele participa.

É a esta simultaneidade que uma filosofia intempestiva responde, entendendo aqui resposta como enfrentamento. É ao mesmo tempo que nos situamos no presente da história e que dele somos arrancados. A existência de um tempo cronológico, como dimensão mais evidente e localizável, a marcação cadenciada de nossas vidas, e um tempo que fratura o tempo cronológico, invadindo sua precisão e regularidade. Aqui nos referimos ao tempo aiônico, tempo que Deleuze, na esteira dos estóicos, desenvolve para tratar dessa dimensão intempestiva do tempo. Um presente sempre puxado pelo passado e futuro simultaneamente, 
“ainda não passado-já passado”. Ele é um tempo que não se deixa compreender, restando como que permanentemente fora de nossas amarras conceituais, um tempo em estado bruto.

O que está em jogo, portanto, é nosso pertencimento ao tempo, nosso ”engajamento”, mas também nossa desfiliação, nosso deslocamento, ou até mesmo, abandono do que é explicitamente contemporâneo.

Agir de maneira intempestiva é não estar filiado a seu tempo, mesmo que para empreender os devidos enfrentamentos àquilo que ele glorifica, seja necessário uma íntima relação:

Se todo grande homem chega a ser considerado, acima de tudo, precisamente como o filho autêntico de seu tempo, e, em todo caso, sofre de todas as suas mazelas com mais força e sensibilidade do que todos os homens menores, então o combate de um tal grande contra seu tempo é, ao que parece, apenas um combate sem sentido e destrutivo contra si mesmo. Mas, justamente, apenas ao que parece, pois o que ele combate em seu tempo é aquilo que o impede de ser grande, e isto para ele significa apenas: ser livre e inteiramente ele mesmo. Disto se segue que sua hostilidade no fundo, está dirigida precisamente contra aquilo, que por certo, está nele mesmo, mas não é propriamente ele mesmo, ou seja, a impura mescla e aproximação do incompatível e do eternamente inconciliável, contra a falsa solda do contemporâneo com sua extemporaneidade; e, afinal, o suposto filho do tempo se mostra apenas como seu enteado. ${ }^{\text {ix }}$

Este filho autêntico de seu tempo parece ir até o fim em seu combate, ir até o esgotamento daquilo que o aniquila, e isto parece que o localiza precisamente no tempo, pois é contra as forças desse tempo que ele empreende suas lutas. Porém, como lembra Nietzsche, essa hostilidade contra seu tempo, é também contra aquilo que nele mesmo expressa esse tempo, mas que não é ele propriamente, ou que pelo menos não coincide com ele absolutamente. O que Nietzsche parece sugerir é uma fenda inconciliável, uma fissura que nos dilacera e engrandece, entre isto a que chamamos "nosso tempo" e o extemporâneo, esse tempo que invade nosso presente, deslocando-nos desse pertencimento exato ao tempo atual, fazendo-nos enteados do “nosso tempo”. E é isto que pode portar alguma novidade.

Número 13: novembro/2009 - abril/2010 
Lutar contra as forças do nosso tempo é enfrentar o hábito da oposição que acaba por encaixar-se naquilo que nosso tempo glorifica. A oposição cabe em nosso tempo, cabe de uma maneira demasiadamente confortável. E é contra este encaixe perfeito, daquilo que nosso tempo aceita e concebe como seu que situamos esta ação “contra o tempo”.

Uma filosofia intempestiva, portanto, ao invés de uma oposição cansada e esperançosa, filiada confortavelmente ao contemporâneo (conceito excessivamente utilizado atualmente), pede a afirmação dos seus desencaixes, os seus rasgos de futuro, inventando-se com eles e descobrindo uma sensibilidade que abrigue sem tentar abarcar, o que já não somos, o que não cabe em nosso tempo, mas que nele insiste.

E o que já não somos não é o que já nos tornamos ou iremos nos tornar, como numa disposição regular do tempo. Mas é a condição mais própria do devir, a de ir junto com aquilo que compõe os encontros deste tempo.

Creio que uma pista disso tudo, reside na inocência, numa espécie de devir-poeta que não sabe o que todo mundo sabe, que não conhece os códigos habituais do mundo, que não funciona com eles. A inocência de quem prefere os despropósitos ao bom senso. ${ }^{\mathrm{x}}$

Uma outra expressão desta inocência é o olhar virgem para o mundo, potência da infância. O olhar distraído das viciadas categorias de compreensão, e por isso fértil. O olhar que também não partilha o que todo mundo sabe, e por isso inventa experimentações diversas e graus de liberdade variáveis.

Deixar que esses olhares invadam nossas relações com o mundo, encharcando nossa sensibilidade de distração e inocência, talvez seja a indicação de uma atmosfera intempestiva, “ação contra o tempo, a favor de um tempo por vir”. Até porque estas são condições que afligem o nosso tempo, e que ele, definitivamente, não glorifica.

\section{Referências Bibliográficas}

BARROS, Manoel. Exercícios de ser Criança. RJ: Salamandra, 1999.

DELEUZE, G. Nietzsche e a Filosofia. Ed Rés, s/d.

Conversações. RJ: Ed.34, 1992.

NIETZSCHE, F. Obras Incompletas. SP: Abril Cultural, 1983.

ZOURABICHVILI, F. Deleuze e o possível (Sobre o involuntarismo na Política) em Deleuze. Uma vida filosófica. RJ: Ed.34, 2001. 
' Artigo originalmente apresentado em setembro de 2009 no II Encontro Nacional do Grupo de Trabalho Filosofar e Ensinar a Filosofar da Associação Nacional de Pós-Graduação em Filosofia (ANPOF), realizado na Universidade Gama Filho, no Rio de Janeiro.

ii Doutoranda da Universidad do Vale do Rio dos Sinos (Unisinos), Rio Grande do Sul. Correio eletrônico: ahelena21@yahoo.com.br

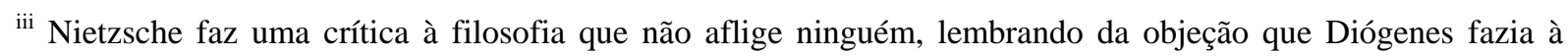
louvação de um filósofo: "O que ele tem de extraordinário para mostrar, ele que durante tanto tempo se entregou à filosofia sem nunca ter afligido ninguém? Com efeito, seria necessário colocar como epitáfio no túmulo da filosofia universitária: Nunca afligiu ninguém." Considerações Extemporâneas, Shopenhauer como Educador, 8.

${ }^{\text {iv }}$ Nietzsche, Considerações Extemporâneas, III, 3-4.

${ }^{v}$ O ensino de filosofia está livre desta necessidade de oposição? Será que este hábito do nosso pensamento não se apresenta para prestar contas eternamente a uma posição primeira que toda oposição acaba por manter viva? Como filosofar e ensinar filosofar de outros modos, assumindo a própria precariedade desta questão que pergunta "como"?

${ }^{v i}$ Deleuze distingue os pares conceituais possível/real de virtual/atual, onde este traz a atualização sempre por linhas diferenciais e aquele, uma relação de identidade correspondente. Neste estudo, porém não aprofundaremos essa distinção.

vii “É preciso falar da criação, como traçando seu caminho entre impossibilidades..." DELEUZE, G. Conversações, p. 166.

viii Zourabichvili, F. Deleuze e o possível (Sobre o involuntarismo na Política) em Deleuze. Uma vida filosófica, p. 353.

${ }^{\text {ix }}$ Considerações Extemporâneas, p.73.

x “(...) Será que os absurdos não são as maiores virtudes da poesia? Será que os despropósitos não são mais carregados de poesia do que o bom senso? (...)” Manoel de Barros, Exercícios de ser Criança. 